\title{
Estimation of The Effect Size Meta Measurement Model with Generalized Method of Moments Approach
}

\author{
Hary Suprihanto ${ }^{1}$, Bambang Widjanarko Otok ${ }^{2}$, Agus Suharsono ${ }^{3}$ \\ \{hary.bma@gmail.com ${ }^{1}$, bambang_wo@statistika.its.ac.id ${ }^{2 *}$,dr.otok.bw@gmail.com²* \\ gmagussuharsono@gmail.com $\left.{ }^{3}\right\}$ \\ Department of Statistics, Faculty of Science and Data Analystics, Institut Teknologi Sepuluh \\ Nopember, Surabaya, Indonesia ${ }^{1,2,3}$
}

\begin{abstract}
Generalization of research results often cannot be made using only one finding, so a synthesis of several research results is needed to obtain an integrated conclusion. The synthesis of several research results through meta-analysis has developed in the study of Structural Equational Modeling (SEM), one of which is the measurement model. The aim of this study is to obtain an estimate of the effect size of the meta-analysis measurement model on the factors that measure the performance of regional drinking water companies. The data used is the performance data of regional drinking water companies in Java. The company's performance is measured based on four main criteria: financial, service, operational, and human resources. Measurement modeling and meta-analysis were carried out using software R. The estimation method used is the Generalized Method of Moments (GMM). The results of this analysis show that the model for performance assessment is a fit model. The model developed meets the requirements for the quality of the fit model, thereby confirming that financial, service, operational, and human resource indicators can be used to measure regional drinking water companies' performance in Java. Besides, through the combined effect size estimation, it can be concluded that human resource and finance is the most dominant indicator in measuring company performance.
\end{abstract}

Keywords: Effect Size, Meta-Anaysis, Measurement Model, GMM

\section{Introduction}

In various applications in statistics, meta-analysis is very useful for synthesizing information about general parameters that underlie interest in various studies [1]. The advantage of meta-analysis is that it can be done solely on the basis of model parameter estimation and standard errors. It can be found that parameter estimates from this analysis are asymptotically efficient under rational assumptions as those from the combined analysis [2]. Furthermore, in its development, meta-analysis can also be carried out in the discussion of structural equational modelling, which includes regression analysis, path analysis, and confirmatory factor analysis (CFA) [3]. The measurement error of a variable is a severe problem in structural model analysis. This results in a lack of construct validity when building a model and weak parameter estimates involving multiple constructs in the structural model [4]. An analysis is needed, namely CFA, to identify latent factors that explain variations and covariances between indicators [5]. The theoretical justification is an absolute requirement in SEM. On the other side, concerning CFA, there are often differences in measuring a variable in theory. 
Further analysis is needed to determine the accuracy of variable measurement through Meta-Confirmatory Factor Analysis (Meta-CFA). Meta-CFA is a combination of two methods: meta-analysis and CFA, which only considers the measurement model and can be considered a particular case in meta-analysis structural equation modelling (MASEM) [6]. Meta-CFA is based on the unifying correlation matrices between units from a number of research units, which are then used as input for CFA to evaluate a number of factor model structures [7]. Meta-CFA can be more advantageous than traditional statistical approaches, as it allows several samples, conditions and measurements to be tested for the model [8]. Several studies on Meta-CFA have been conducted, some of which are evaluation of structure of the Hospital Anxiety and Depression Scale (HADS) anxiety variables [9], inconsistencies in measuring personality variables using the big five traits indicator [10], and the ambiguity of measuring the variable Figural Torrance Tests of Creative Thinking [11].

Research on Meta-CFA related to the assessment of organizational performance measurement models is very rare. This is because the organizational performance model is usually a standard model that is not evaluated in a short period of time. Evaluation of quality standards and performance services of regional drinking water companies in Java Indonesia is an activity of assessing and measuring each aspect of performance appraisal so that it can be seen the quality and achievements in providing drinking water supply services to the community. The performance evaluation indicators of regional water companies currently used are the result of development in 2010. The performance indicators consist of four aspects: finance, services, operations, and human resources. On the other side, the differences in the regional drinking water companies' characteristics in each city often result in different measurements. The difference in performance measurement is interesting to study to determine the best performance measurement model.

The performance aspects of regional drinking water companies cannot be measured directly, but through known indicators, in such a way that the appropriate statistical analysis is Meta-CFA. The results of previous research on the performance of regional drinking water companies in Java are minimal, so that it is not possible to obtain a correlation matrix which is the input of Meta-CFA, so in this study, it is assumed that Meta-CFA on the factors that measure the performance of regional drinking water companies in Java as a result of annual research begins from 2010 to 2018. The research results in each period of the year can produce different conclusions so that in this study, a Meta-CFA will be conducted on the factors that measure the performance of regional drinking water companies in Java.

\section{Method}

The data used in this analysis are secondary data in the form of publications on the performance data of regional drinking water companies in Java for the period 2010-2018, which is the result of annual data processing organized by the agency to improve the implementation of the drinking water supply system. The observation unit in performance measurement is annual research from 2010 to 2018. The CFA modeling results from the subsequent annual research are used as a unit of analysis in meta-analysis with the GMM approach to define factors that assess the performance of regional drinking water companies in Java.

This study uses eight indicators that measure the performance of regional drinking water companies in Java. Based on technical guidelines for evaluation of performance indicators by 
the agency of drinking water supply system in 2010, the indicator variables used in this study are as follows:

1. Finance $\left(\mathrm{X}_{1}\right)$

- Operating Ratio: Ratio to measure the level of efficiency of expenses incurred to generate income

- Billing Effectiveness: Percentage of the effectiveness of collection activities on the proceeds from sales of water

- Solvency: A measure of the company's ability to guarantee long-term liabilities with its assets

2. Services $\left(\mathrm{X}_{2}\right)$

- $\quad$ Technical Service Coverage: Percentage of total population served by the company compared to the population in the service area

- Customer Complaint Settlement: Measure to assess the company's response to customer complaints

3. Operations $\left(\mathrm{X}_{3}\right)$

- Production Efficiency: Production utilization factor to measure the efficiency of the production system

- Water Loss Rate: The difference between the water entering the distribution unit and billed water during the evaluation period

4. Human Resources $\left(\mathrm{X}_{4}\right)$

- Employee to Customer Ratio: the level of efficiency and effectiveness of the use of labor to provide services to customers

The observation unit used in this study is the correlation matrix of the CFA modeling results of the factors that affect regional water companies' performance in Java. The indicator variable in CFA modeling in this study is a latent variable with formative measurements. To obtain a correlation matrix in each research year using the factor score weights from the SmartPLS 3.0 program results multiplied by each indicator's data. Factor score derives from latent variables, both endogenous and exogenous, in the measurement model [12]. The steps taken to answer the research objectives using the Meta-CFA method on the factors that measure the performance of regional drinking water companies in Java are as follows:

1. Determine the value of the factor score weights on each CFA indicator variable (Finance, Services, Operations, Human Resources) using the SmartPLS 3.0 program for each year.

2. Calculation of the vector score factor indicator (Finance, Services, Operations, Human Resources) with the formula:

$F S=X_{n x p} W_{p x 1}^{\prime}$

FS: Factor Score

$\mathrm{X}$ : Indicator Data

W: Weights

Furthermore, the value obtained in this step becomes the CFA modeling data each year.

3. Conduct CFA modeling on the factors that measure company performance every year from 2010 to 2018 with the following conceptual model: 


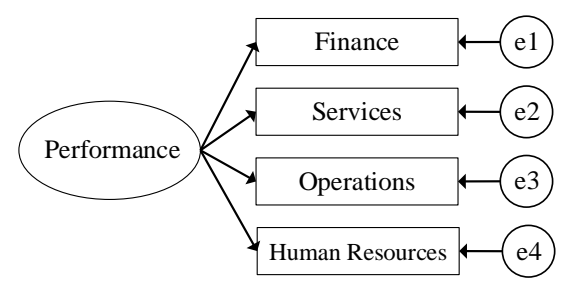

Fig. 1. Conceptual Model of Performance Measurement

4. Develop a correlation matrix for each year.

5. Conduct a homogeneity test on the research correlation matrices.

6. Calculate the combined correlation matrix with fixed effects in homogeneous cases or random effects in heterogeneous cases.

7. Use the combined correlation matrix as input in the next step.

8. Perform a model fit test.

\section{Results and Discussion}

The correlation matrix produced in step 3 is the effect size generated in each year. Table 1 below presents the effect size results from nine annual studies:

Table 1. Result of Effect Size for Each Year

\begin{tabular}{|c|c|c|c|c|c|c|c|c|c|c|c|c|c|}
\hline \multirow[t]{3}{*}{ Year } & \multirow[t]{3}{*}{$\mathbf{n}$} & \multicolumn{12}{|c|}{ Correlations } \\
\hline & & \multicolumn{3}{|c|}{$\mathrm{X}_{1}$} & \multicolumn{3}{|c|}{$\mathrm{X}_{2}$} & \multicolumn{3}{|c|}{$\mathrm{X}_{3}$} & \multicolumn{3}{|c|}{$\mathrm{X}_{4}$} \\
\hline & & $\mathrm{X}_{2}$ & $\mathrm{X}_{3}$ & $\mathrm{X}_{4}$ & $\mathrm{X}_{1}$ & $\mathrm{X}_{3}$ & $\mathrm{X}_{4}$ & $\mathrm{X}_{1}$ & $\mathrm{X}_{2}$ & $\mathrm{X}_{4}$ & $\mathrm{X}_{1}$ & $\mathrm{X}_{2}$ & $X_{3}$ \\
\hline 2010 & 107 & $\begin{array}{c}- \\
0.191\end{array}$ & $\begin{array}{c}- \\
0.198\end{array}$ & 0.361 & $\begin{array}{c}- \\
0.191\end{array}$ & 0.237 & $\begin{array}{c}- \\
0.433\end{array}$ & $\begin{array}{c}- \\
0.198\end{array}$ & 0.237 & $\begin{array}{c}- \\
0.450\end{array}$ & 0.361 & $\begin{array}{c}- \\
0.433\end{array}$ & $\begin{array}{c}- \\
0.450\end{array}$ \\
\hline 2011 & 107 & $\begin{array}{c}- \\
0.043\end{array}$ & $\begin{array}{c}- \\
0.051\end{array}$ & 0.086 & $\overline{-}$ & 0.237 & $\begin{array}{c}- \\
0.398\end{array}$ & $\begin{array}{c}- \\
0.051\end{array}$ & 0.237 & $\begin{array}{c}- \\
0.471\end{array}$ & 0.086 & $\begin{array}{c}- \\
0.398\end{array}$ & $\begin{array}{c}- \\
0.471\end{array}$ \\
\hline 2012 & 107 & $\begin{array}{c}- \\
0.042\end{array}$ & 0.046 & 0.070 & 0.042 & 0.272 & 0.413 & 0.046 & 0.272 & 0.453 & 0.070 & 0.413 & $\begin{array}{c}- \\
0.453\end{array}$ \\
\hline 2013 & 107 & $\begin{array}{c}- \\
0.201\end{array}$ & $\begin{array}{c}- \\
0.221\end{array}$ & 0.357 & $\begin{array}{c}- \\
0.201\end{array}$ & 0.300 & $\begin{array}{c}- \\
0.486\end{array}$ & $\begin{array}{c}- \\
0.221\end{array}$ & 0.300 & $\begin{array}{c}- \\
0.533\end{array}$ & 0.357 & $\begin{array}{c}- \\
0.486\end{array}$ & $\begin{array}{c}- \\
0.533\end{array}$ \\
\hline 2014 & 107 & $\begin{array}{c}- \\
0.060\end{array}$ & 0.083 & 0.099 & $\begin{array}{c}- \\
0.060\end{array}$ & $\begin{array}{c}- \\
0.333\end{array}$ & $\begin{array}{c}- \\
0.397\end{array}$ & 0.083 & $\begin{array}{c}- \\
0.333\end{array}$ & 0.552 & 0.099 & $\begin{array}{c}- \\
0.397\end{array}$ & 0.552 \\
\hline 2015 & 107 & 0.119 & $\begin{array}{c}- \\
0.099\end{array}$ & 0.023 & 0.119 & $\begin{array}{c}- \\
0.012\end{array}$ & 0.003 & $\begin{array}{c}- \\
0.099\end{array}$ & $\begin{array}{c}- \\
0.012\end{array}$ & $\begin{array}{c}- \\
0.002\end{array}$ & 0.023 & 0.003 & $\begin{array}{c}- \\
0.002\end{array}$ \\
\hline 2016 & 107 & $\begin{array}{c}- \\
0.022\end{array}$ & 0.031 & 0.053 & $\begin{array}{c}- \\
0.022\end{array}$ & $\begin{array}{c}- \\
0.232\end{array}$ & $\begin{array}{c}- \\
0.395\end{array}$ & 0.031 & $\begin{array}{c}- \\
0.232\end{array}$ & 0.552 & 0.053 & $\begin{array}{c}- \\
0.395\end{array}$ & 0.552 \\
\hline 2017 & 107 & $\begin{array}{c}- \\
0.137\end{array}$ & $\begin{array}{c}- \\
0.084\end{array}$ & $\overline{-}$ & $\begin{array}{c}- \\
0.137\end{array}$ & 0.012 & 0.003 & $\begin{array}{c}- \\
0.084\end{array}$ & 0.012 & 0.002 & $\overline{-}$ & 0.003 & 0.002 \\
\hline 2018 & 107 & 0.139 & 0.067 & $\begin{array}{c}- \\
0.009\end{array}$ & 0.139 & 0.009 & $\begin{array}{c}- \\
0.001 \\
\end{array}$ & 0.067 & 0.009 & $\begin{array}{c}- \\
0.001 \\
\end{array}$ & $\begin{array}{c}- \\
0.009 \\
\end{array}$ & $\begin{array}{c}- \\
0.001\end{array}$ & $\begin{array}{c}- \\
0.001\end{array}$ \\
\hline
\end{tabular}

Table 1 shows that the resulting effect sizes vary widely, for example in 2010 the largest effect size with a positive value (0.361) lies in the relationship between finance and human 
resources, while in 2011 the largest positive effect size (0.237) lies in the relationship between services and operations. Likewise, in the following years, the analysis results were relatively different. This effect size variation underlies further analysis to obtain a combined effect size.

Two-Stage Structural Equational Modelling (TSSEM) approach with GMM estimation has two steps of analysis: testing the homogeneity which results in the estimated effect size of the combined correlation matrix and the model suitability test from the combined effect size estimation results. The model homogeneity test results obtained Q-statistic of effect sizes 946.9391 and p-value $<0.001$, so it is a TSSEM random effect model. The resulting combined correlation matrix is:

$R_{\text {pooled }}=\left[\begin{array}{llllll} & \text { Performance } & \text { Human Resources } & \text { Operations } & \text { Services } & \text { Finance } \\ \text { Performance } & 1 & 0.591 & -0.112 & -0.303 & 0.460 \\ \text { Human Resources } & 0.591 & 1 & -0.089 & -0.280 & 0.113 \\ \text { Operations } & -0.112 & -0.089 & 1 & 0.054 & -0.057 \\ \text { Services } & -0.303 & -0.280 & 0.054 & 1 & -0.049 \\ \text { Finance } & 0.460 & 0.113 & -0.057 & -0.049 & 1\end{array}\right]$

The combined effect size clarifies the results of the meta analysis. The resulting matrix shows that human resources and finance each have the strongest relationship with performance with a correlation of 0.591 and 0.460 , while operations and serices have a relatively low correlation.

The following table is the estimated value of the loading factor for each indicator against the latent variable:

Table 2. Factor loading estimation

\begin{tabular}{lcccc}
\hline \multicolumn{1}{c}{ Indicator } & Estimate & Std.Error & z value & $\mathbf{P}(>|\mathbf{z}|)$ \\
\hline Human Resources & $7.4314 \mathrm{e}-01$ & $8.7985 \mathrm{e}-02$ & 8.4462 & $<2.2 \mathrm{e}-16 * * *$ \\
Operations & $6.0122 \mathrm{e}-09$ & $3.3160 \mathrm{e}-01$ & 0.0000 & 1 \\
Services & $-6.8756 \mathrm{e}-10$ & $9.1805 \mathrm{e}-02$ & 0.0000 & 1 \\
Finance & $6.5394 \mathrm{e}-01$ & $1.0519 \mathrm{e}-01$ & 6.2166 & $5.082 \mathrm{e}-10 * * *$ \\
\hline
\end{tabular}

It can be seen from Table 2 that human resources and finance can measure the performance variable well. This is indicated by the resulting $\mathrm{p}$-value $<0.001$, while the operations and services indicator shows an invalid measurement. In addition, based on Godness of Fit Indices, RMSEA value is $\leq 0.08$, implying that the model has verified the measurement of performance variables.

\section{Conclusion}

The conclusion that can be drawn from the results of the analysis is that the resulting MetaCFA model is fit and can be used to explain the performance of regional drinking water companies in Java. The resulting combined effect size value shows that the human resource and financial indicators are the indicators with the highest measurement contribution to performance, while the other two indicators, namely the operational and service indicators, show a weak measurement contribution. 


\section{References}

[1] DerSimonian R, Laird N. Meta-analysis in clinical trials. Control Clin Trials 1986. https://doi.org/10.1016/0197-2456(86)90046-2.

[2] Olkin I, Sampson A. Comparison of Meta-Analysis Versus Analysis of Variance of Individual Patient Data. Biometrics 1998. https://doi.org/10.2307/2534018

[3] Otok BW, Standsyah RE, Suharsono A, Purhadi. Development of model poverty in Java using Meta-Analysis Structural Equation Modeling (MASEM). AIP Conf. Proc., 2019. https://doi.org/10.1063/1.5139810.

[4] Bagozzi RP, Yi Y, Phillips LW. Assessing Construct Validity in Organizational Research. Adm Sci Q 1991. https://doi.org/10.2307/2393203.

[5] Brown T. Confirmatory Factor Analysis for Applied Research, Second Edition. 2015.

[6] Cheung MWL, Chan W. Meta-analytic structural equation modeling: A two-stage approach. Psychol Methods 2005. https://doi.org/10.1037/1082-989X.10.1.40.

[7] Cheung MWL. Fixed-and random-effects meta-analytic structural equation modeling: Examples and analyses in R. Behav Res Methods 2014. https://doi.org/10.3758/s13428-013-0361-y.

[8] Cheung MW-L. Meta-analytic structural equation modeling. Meta-Analysis, 2015. https://doi.org/10.1002/9781118957813.ch7.

[9] Norton S, Cosco T, Doyle F, Done J, Sacker A. The Hospital Anxiety and Depression Scale: A meta confirmatory factor analysis. J Psychosom Res 2013. https://doi.org/10.1016/j.jpsychores.2012.10.010.

[10] Muncer SJ. The general factor of personality: Evaluating the evidence from meta-analysis, confirmatory factor analysis and evolutionary theory. Pers Individ Dif 2011. https://doi.org/10.1016/j.paid.2011.06.029.

[11] Said-Metwaly S, Fernández-Castilla B, Kyndt E, Van den Noortgate W. The Factor Structure of the Figural Torrance Tests of Creative Thinking: A Meta-Confirmatory Factor Analysis. Creat Res J 2018. https://doi.org/10.1080/10400419.2018.1530534.

[12] Anekawati A, Otok BW, Purhadi P, Sutikno S. Lagrange multiplier test for spatial autoregressive model with latent variables. Symmetry (Basel) 2020. https://doi.org/10.3390/SYM12081375. 